\title{
CONSPECIFIC MIMICS AND LOW HOST PLANT AVAILABILITY REDUCE EGG LAYING BY HELICONIUS ERATO PHYLLIS (FABRICIUS) (LEPIDOPTERA, NYMPHALIDAE)
}

\author{
Elna Mugrabi-Oliveira ${ }^{1}$ \\ Gilson R.P. Moreira ${ }^{2}$
}

\begin{abstract}
Oviposition response of Heliconius erato phyllis (Fabricius, 1775) (Lepidoptera, Nymphalidae) to variation in host plant availability, Passiflora suberosa Linnaeus (Passifloraceae), and to presence of conspecific eggs and larvae was determined through choice experiments performed under insectary conditions. Freeze dried, painted eggs and larvae were used as mimics for testing presence of conspecific effects. Females laid more eggs on intact $P$. suberosa shoots without conspecifics than on those with $H$. erato phyllis egg and first instar mimics in both simultaneous and sequential choice trials. Oviposition response to variation in host plant availability was determined through no-choice trials, under host plant densities varying from 0.3 to 8.3 plants per female. Number of eggs laid per plant decreased exponentially with an increase in plant availability. On the contrary, daily oviposition rates (eggs/female/day) increased with an increase in plant number, and levelled off when the number of plants available for oviposition was greater than potential fecundity of females. Thus, it is inferred from the results that females assess egg and larval load and prefer to lay eggs on shoots free from conspecifics. It is also inferred that they are able to recognize plant abundance and are unwilling to lay more than one egg per shoot even when host availability is scarce, as judged by reduction in daily oviposition rates under low host plant number. The consequences of laying isolated eggs on $P$. suberosa shoots are discussed from the viewpoint of intraspecific competition in the larval stage of $H$. erato phyllis.

KEY WORDS. Heliconius, Passiflora, oviposition behavior, egg-load assessment, plant density recognition
\end{abstract}

Oligophagous insects typically choose host-plants for oviposition, their larval hosts being indirectly determined through oviposition site selection. Their host-choices are based not only upon inter-specific plant attributes but also on variation within individual plants, as for example on host size, age and phenology. A close association is commonly found between host-plant species they choose from and performance regarding their survivorship, developmental rates and size attained in the larval stage. As a consequence, it has been inferred that host choices made by oligophagous insects are at least in part mediated by suitability of plant species, or

1) Pós-graduacão em Entomologia, Departamento de Zoologia, Universidade Federal do Paraná. Caixa Postal 19020, 81531-990 Curitiba, Paraná, Brasil.

2) Correspondence to: Departamento de Zoologia, Instituto de Biociências, Universidade Federal do Rio Grande do Sul. Avenida Paulo Gama 40, 90046-900 Porto Alegre, Rio Grande do Sul, Brasil.

e-mail: grpm@if.ufrgs.br 
plant parts and tissues, as larval food (see WIKLUND 1975; CATES 1980; SINGER 1986; ThOMAS 1987; Jones 1991; BERnAYs \& ChapMAN 1994; MUGRABI-OlIVEIRA \& MOREIRA 1996).

Presence of conspecifics on host plants may also influence performance of herbivorous insects under limited food conditions. Thus, females that discriminate in favor of plants without conspecific eggs and larvae might have higher reproductive performance compared to those that do not discriminate based upon the presence of conspecifics. Such a discriminatory behavior is supposedly mediated by larval competition, and has been described for a number of insect species (see JONES 1991), including several butterflies, such as pierids (ROTHSCHILD \& SCHOONHOVEN 1977; WIKLUND \& AHRBAERG 1978; SHAPIRO 1981), papilionids (RAUSHER 1979), ithomiines (VASCONCELLOS-NETO \& MONTEIRO 1993) and heliconiines (WILLIAMS \& GILBERT 1981).

In addition, relative abundance of host-plants has been also shown to affect ovipositing behavior of some insects in particular. Parasitoid wasps, for example, alter their host-searching behavior, daily oviposition rates and offspring sex ratio, among other reproductive parameters, according to variation in host availability (see VINSON 1981; CHARNOV 1982; WeLLINGS 1991). Some butterfly species are also known to alter use of preferred host-plants as a function of host-plant abundance (SOLOMON 1981; COURTNEY \& FORSBERG 1988). Little is known, however, about the potential effects of variation in abundance of a given host-plant species upon other butterfly reproductive behavior, such as in relation to searching, choice and acceptance of host-plants for oviposition. In this paper, it is presented evidence that females of Heliconius erato phyllis (Fabricius, 1775), a commonly found passionvine butterfly in southern Brazil, recognize relative abundance of host plants and alter daily oviposition rates under low host-plant availability besides assessing eggand larval-load.

\section{MATERIALS AND METHODS}

Effects of presence of conspecific and of variation in host plant (Passiflora suberosa Linnaeus) availability on $H$. erato phyllis host plant selection were determined through ovipositional choice trails (sensus SINGER 1986). The study was performed under outdoor insectary conditions at the Zoology Department of Federal University of Rio Grande do Sul State, Porto Alegre city, from April to May 1995. Insects and plants used in the tests were collected from populations of Aguas Belas Experimental Station, Viamão County. They were maintained in an outdoor screened insectary, following methodology described in detail by MUGRABI-OLIVEIRA \& MOREIRA (1996). Experiments were conducted in $2.0 \times 3.0 \times 1.8 \mathrm{~m}$ sections of additional insectaries.

Sequential and simultaneous choice trials were concurrently carried out to determine effects of presence of conspecific mimics. Mimics were carefully stuck to plants with white glue (Tenaz ${ }^{\circledR}$ ) to $P$. suberosa shoot cuttings, and offered for oviposition. Cuttings were placed in water filled, plastic bottles that were randomly positioned (about $50 \mathrm{~cm}$ from each other) in the insectary compartments. Five 
treatments were used in both sequential and simultaneous choice trials: 1) shoot cutting without conspecific mimic (T);2) with egg on terminal bud (E); 3) with first-instar larva on terminal bud (L1); 4) with fifth-instar larva on second open leaf (L5); 5) with egg and larval mashed on terminal bud (C, control). Only one female was tested each day in the simultaneous choice trials, and per treatment in the sequential choice trials. Each experiment lasted fifteen days (= number of replicates). In the sequential choice trials, the experimental period ( 9 a.m. -3 p.m.) was divided into two 3-hour intervals, and females were moved among the insectary compartments at the end of these pre-determined time intervals.

Freeze dried specimens of $H$. erato phyllis eggs and larvae (Fig. 1), obtained from insectary rearings, were used as mimics in-such tests. For preparation, they were killed in boiling water, immediately frozen at $-10^{\circ} \mathrm{C}$ and then freeze dried. After, they were carefully watercolor-painted under a stereomicroscope, following the natural color pattern for $H$. erato phyllis. Cuttings used as oviposition substrates had intact terminal buds and three open leaves. They were placed in water filled, plastic bottles. A ratio of five cuttings per female was used for each treatment in both sequential and simultaneous choice trials.
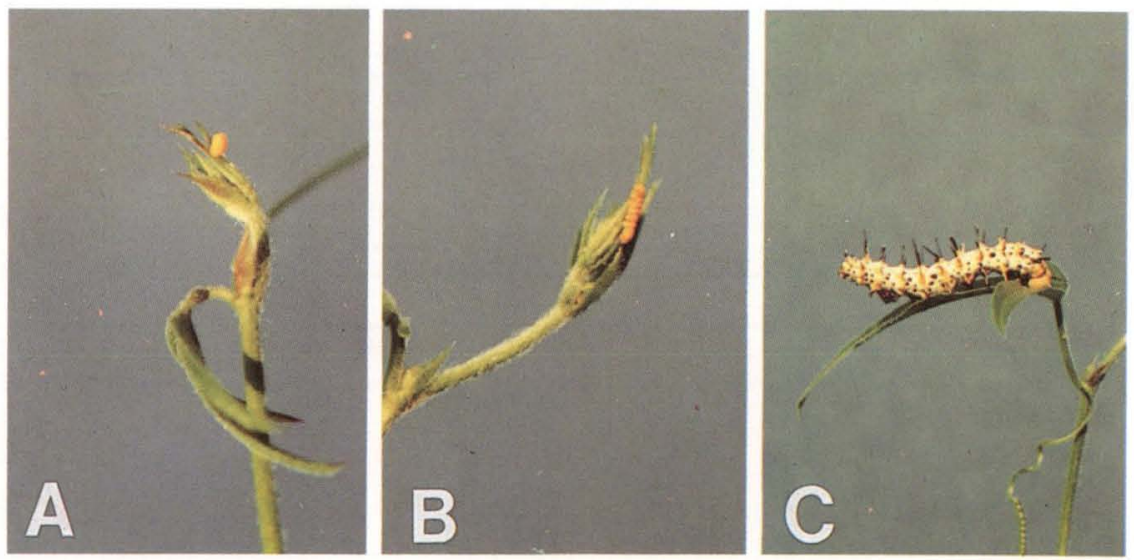

Fig. 1. Conspecific mimics of $H$. erato phyllis on shoots of $P$. suberosa. (A) Egg, (B) first-instar larva, (C) fifth-instar larva.

No-choice trials were conducted to determine shoot availability effects. $P$. suberosa cuttings bearing three open leaves and intact terminal bud, also placed in water filled, plastic bottles, were offered daily for oviposition in variable number per insectary section $(1,5,10,15,20$ and 25). Groups of three females were introduced every day in each section, resulting in densities ranging from 0.33 to 8.33 cuttings per female (= treatments). The experimental period lasted for nine hours ( 8 a.m. -5 p.m.), and each treatment was replicated ten times. 
In both experiments, $P$. suberosa cuttings were inspected for egg deposition at the end of the pre-determined time-intervals described previously, when eggs were counted and removed. To control for variation among individuals, females and cuttings were randomly selected, and never used either consecutively nor twice in a given trial. Insectary sections, and order of treatments to be tested in a given day in the sequential choice trials, were also randomized.

\section{RESULTS}

Presence of conspecific mimics on $P$. suberosa shoots deterred oviposition by $H$. erato phyllis. In the simultaneous choice trials, females laid a significantly greater number of eggs on intact shoots without mimics and control than on those where eggs, first- and fifth-instar larvae were present (Fig. 2A). In the sequential choice trials, oviposition was significantly lower on shoots with eggs and first instar larvae than on those without conspecific mimics and control (Fig. 2B). There was no significant statistical differences between number of eggs laid on intact shoots without mimics and control treatment in both trials (Fig. 2A,B).

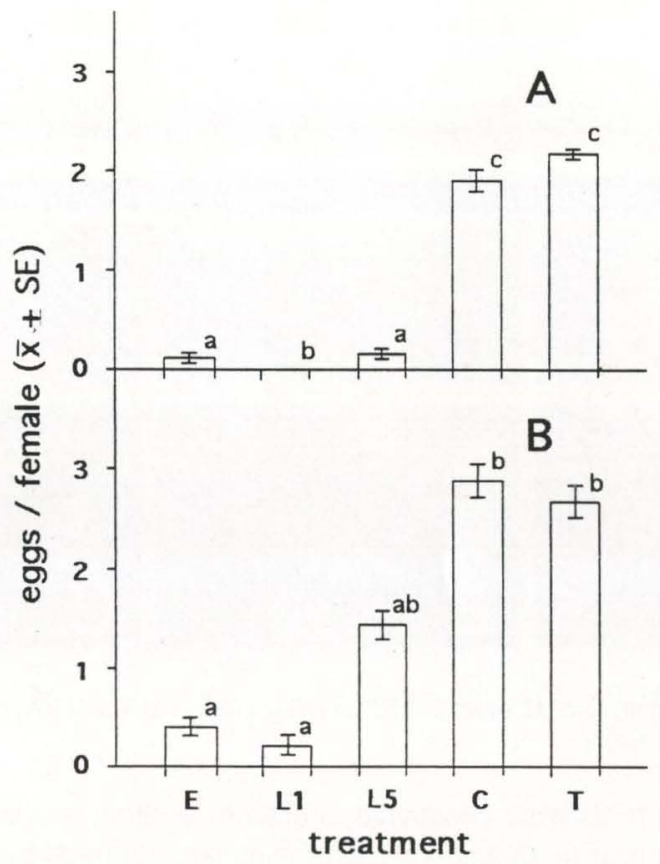

Fig. 2. Oviposition response of $H$. erato phyllis to presence of conspecific mimics on $P$. suberosa shoots, under simultaneous (A) and sequential (B) choice trials. (E) Egg; (L1) first-instar larva; (L5) fifth-instar larva; (C) mashed egg, larva and glue (control); (T) intact shoot without conspecific. Values followed by the same letter are not significantly different (Anova log transformed data, $n=75$, alpha $=0.05$; Tukey multiple comparison tests, alpha $=0.05$ ). 
Variation in density of $P$. suberosa shoots offered for oviposition affected egg-laying response of $H$. erato phyllis. The average number of eggs laid ranged from $3.1 \pm 1.84$ eggs per shoot at a ratio of 0.33 cuttings offered per female to $0.38 \pm$ 0.38 eggs per shoot, at 8.33 cuttings offered per female. In this interval, number of eggs laid per cutting decreased exponentially with an increase in number of plants offered for oviposition $(1 / y=0.27 x+0.64, r=0.71, p<0.01, n=60)$ (Fig. 3). In average, daily oviposition rates ranged from 1.04 to 3.17 eggs per female. They increased linearly from 1.04 to 3.03 eggs per female with an increase in number of shoots offered for oviposition in the interval of 0.33 to 5 shoots offered per female $(y=0.42 x+0.90, r=0.68, p<0.01, n=40)$, and then levelled off (Fig. 4).

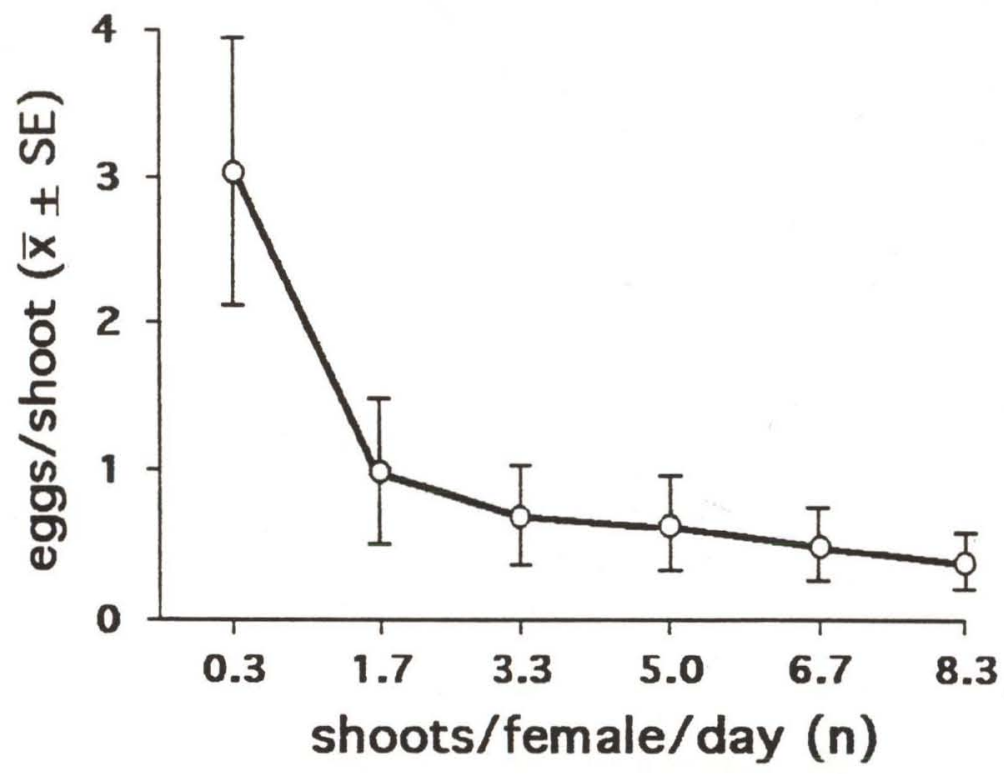

Fig. 3. Variation in number of eggs laid per $P$. suberosa shoot by $H$. erato phyllis females as a function of number of shoots offered for oviposition under insectary conditions.

\section{DISCUSSION}

Ovipositional choice tests demonstrated that $H$. erato phyllis females assess egg and larval-load on P. suberosa plants before oviposition. In both sequential and simultaneous choice trials, they preferred to oviposit on shoots without eggs and first-instar larvae compared to those with conspecifics. Deposition of more than one egg per shoot occurred, but only under low number of shoots offered for oviposition. The number of eggs laid per shoot decreased exponentially with an increase in number of shoots offered for oviposition. Thus, it is expected deposition of more than one egg per shoot would only occur in passion vine populations where shoots free from conspecifics are unavailable or scarce. None of egg-bearing shoots collected from a P. suberosa population of Águas Belas Experimental Station had more than one conspecific egg or larva, or any immature stage of other passion vine 
butterflies (E. Mugrabi-Oliveira, unpublished data). Field observations carried out throughout the neotropics have suggested that in general $H$. erato lays isolated eggs on terminal portion of several passion vine species (e.g., CRANE 1955; BENSON et al. 1976; BENSON 1978; LOPES 1991; MUGRABI-OLIVEIRA \& MOREIRA 1996).

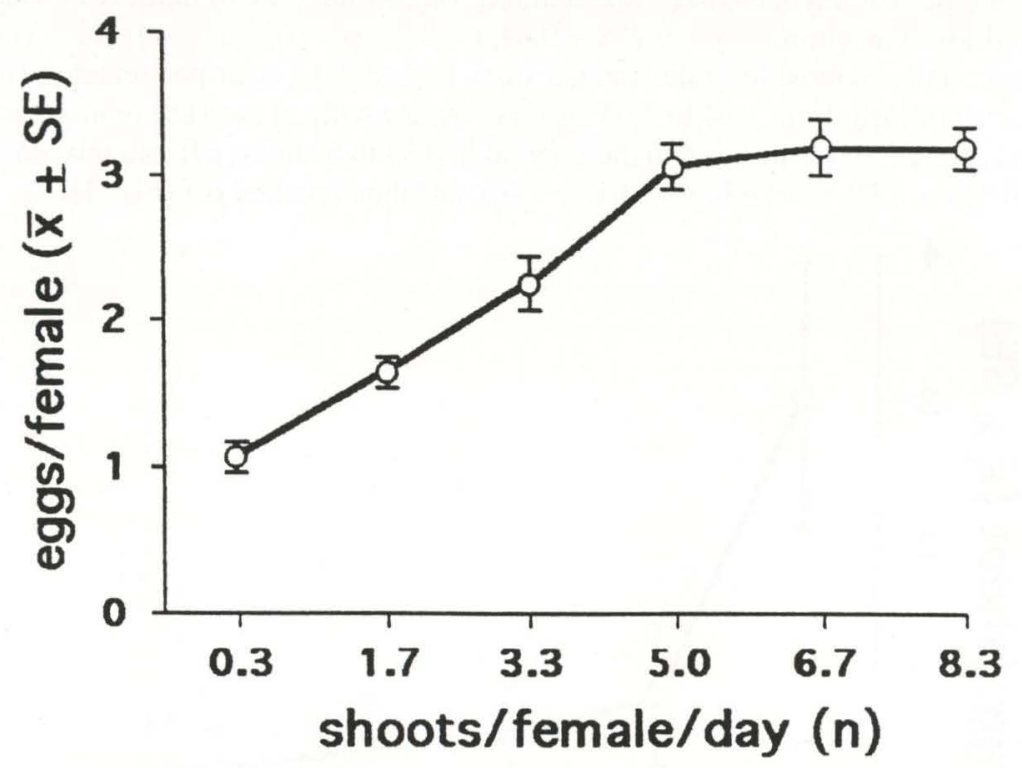

Fig. 4. Daily oviposition rates of $H$. erato phyllis as a function of number of $P$. suberosa shoots offered for oviposition under insectary conditions.

Egg-load assessment had already been experimentally demonstrated for another Heliconius species (Williams \& GilberT 1981). It is unknown to us whether such a discriminatorial behavior had been reported for the larval stage of heliconian butterflies. Two aspects of $H$. erato phyllis $-P$. suberosa interactions indicate egg- and larval-load assessments have adaptive value for this passion vine butterfly. First, a successful development of the two first larval instars of $H$. erato phyllis depends strongly upon feeding on young tissue, located on terminal portion of shoots (D. Rodrigues and G.R.P. Moreira, unpublished data). Furthermore, leaf area of most shoots in a $P$. suberosa population studied by MUGRABI-OLIVEIRA \& MOREIRA (1996) was lower than that required for completion of $H$. erato phyllis larval development. Thus, depending on the shoot a given egg is laid, there may be both qualitative and quantitative food limitation for one $H$. erato phyllis larva. As a consequence, deposition of supernumerary eggs on these shoots would lead to intra-specific competition in the larval stage. Second, older larvae of those heliconian species that lay isolated eggs on shoot tips, as in the case of H. erato phyllis, usually cannibalize young larvae and eggs (see BENSON 1978). Thus, a discriminatory behavior during oviposition would prevent wastage of eggs. As it also seems to be the case for some insect parasitoids (WELLINGS 1991), this factor could be 
important in terms of $H$. erato phyllis reproductive success, since this butterfly has reduced daily oviposition rates (lower than four eggs/female/day, in average).

In general, butterflies assess egg-load on their host-plants either directly by vision (WIKLUND \& AHRBERG 1978; SHAPIRO 1981; RAUSHER 1979) or chemically, through the presence of deterrent pheromones (SCHOONHOVEN et al. 1990; THIERY \& LEQUERE 1991; THIERY et al. 1992). Heliconians are considered to have a good sense of vision, which includes color identification and associative learning (CRANE 1955; SWIHART 1971). While aligning on hosts, females carefully inspect plant parts (BENSON et al. 1976; BENSON 1978; GILBERT 1991), apparently identifying by vision the presence of conspecifics (WILLIAMS \& GILBERT 1981). This was probably the case in the present study. There was no significant statistical difference between the number of eggs laid on shoots without conspecific and control treatment, thus suggesting that chemical compounds, if present, did not play a major role on conspecific recognition.

The results showed that daily oviposition rates of $H$. erato phyllis are influenced by the relative abundance of Passiflora shoots. Potential fecundities were not realized on a daily basis, under a design of a reduced number of shoots free from conspecifics, as fecundities decreased linearly with a decrease in the number of shoots offered for oviposition in the trials. Conversely, number of eggs laid per shoot increased exponentially under low number of shoots offered for oviposition. There is no reason to think these events are independent. In other words, females may have decreased their oviposition rates in the trials not only due to a decrease in number of shoots offered for oviposition, but also as a result of an increase in number of other eggs laid per shoot in such situation. To adjust oviposition rates to variation in availability of suitable host-plants for oviposition might be very important for the reproductive success of $H$. erato, mainly in tropical areas where passion vines may occur at relatively low densities, and where the existence of female competition for oviposition sites among these butterflies has been suggested (BENSON et al. 1976; BENSON 1978).

The physiological consequences of decreasing daily oviposition rates remain unknown for $H$. erato phyllis. In a close related species, Heliconius charitonius oviposition is deterred by overcast or cold weather, and oocyte resorption may occur in case of persistence of unfavorable conditions for several days (DUNLAP-PIANKA et al. 1977). Oviposition retention and oocyte resorption with posterior use of corresponding nutrients in oogenesis has been noted for several lepidopteran species (see ENGELMANN 1970). One would expect these biological phenomena to occur among derived heliconiine lineages (e.g. Heliconius), which show comparatively reduced daily oviposition rates associated with great longevity and extensive periods of reproductive activity. Heliconian species probably adjust their ovarian dynamics to adverse weather and to scarcity of suitable host-plants through retention of mature oocytes, or oogenesis interruption and oocyte resorption. This aspect needs further investigation. 


\begin{abstract}
ACKNOWLEDGEMENTS. Aldo M. Araújo gave technical support and encouraged us to start with Heliconius-Passiflora studies. Simone Rossetto performed freeze drying of the specimens used as mimics. We are grateful to Catherine N. Duckett (University of Puerto Rico), Nicoleta T.N. Sabetzki (EPAGRI) and Aldo M. Araújo (UFRGS) for suggestions that improved earlier drafts of the manuscript. Financial support for this study came from a CNPq Scholarship (M.Sc. Thesis) granted to E. Mugrabi-Oliveira.
\end{abstract}

\title{
REFERENCES
}

BENSON, W.W. 1978. Resource partitioning in passion vine butterflies. Evolution 32: 493-518.

BENSON, W.W.; K.S. BROWN JR. \& L.E. GILBERT. 1976. Coevolution of plants and herbivores: passion flower butterflies. Evolution 29: 659-680.

BERNAYS, E.A \& R.F. CHAPMAN. 1994. Host-plant selection by phytophagous insects. Chapman \& Hall, 312p.

CATES, R.G. 1980. Feeding patterns of monophagous, oligophagous, and polyphagous insect herbivores; the effect of resource abundance and plant chemistry. Oecologia 46: 22-31.

Charnov, E.L. 1982. The theory of sex allocation. Princeton, Princeton University Press, 355p.

COURTNEY, S.P. \& J. ForSBERG. 1988. Host use by two pierid butterflies varies with host density. Func. Ecol. 2: 67-75.

CRANE, J. 1955. Imaginal behavior of a Trinidad butterfly, Heliconius erato hydara Hewitson, with special reference to the social use of color. Zoologica 40: 167-195.

DunlaP-PIANKA, H.; C.L. Boggs \& L.E. GilberT. 1977. Ovarian dynamics in Heliconiine butterflies: programmed senescence versus eternal youth. Science 197: 487-490.

Engelmann, F. 1970. The physiology of insect reproduction. Pergamon Press, $307 p$.

GILBERT, L.E. 1991. Biodiversity of a Central American Heliconius community: pattern, process, and problems, p.403-427. In: P.W. PRICE; T.L. LEWINSOHN; G.W. FERnANDES \& W.W. BENSON (Eds). Plant-animal interactions: evolutionary ecology in tropical and temperate regions. John Wiley \& Sons.

JONES, R.E. 1991. Host location and oviposition on plants. p.139-171. In: W.J. BAILEY \& J. RIDSDILL-SMITH (Eds). Reproductive behavior of insects: individuals and populations. Chapman \& Hall.

LOPES, F.S. 1991. Padrões sazonais e evolução do uso de plantas hospedeiras de larvas por Heliconius erato phyllis (L.) (Lepidoptera, Nymphalidae) na Serra do Japi, São Paulo. Unpublished Ph.D. Dissertation, Instituto de Biologia, Universidade Estadual de Campinas, Campinas, 119p.

Mugrabi-Oliveira, E. \& G.R.P. MoreirA. 1996. Size of and damage on shoots of Passiflora suberosa (Passifloraceae) influence oviposition site selection of Heliconius erato phyllis (Lepidoptera, Nymphalidae). Revta bras. Zool.

RAUSHER, M.D. 1979. Egg recognition: its advantage to a butterfly. Anim. Behav. 
27: 1034-1040.

RothschiLD, M. \& L.M. Schoonhoven. 1977. Assessment of egg load by Pieris brassicae (Lepidoptera: Pieridae). Nature 266: 352-355.

SCHOONHOVEN, L.M.; E.A.M. BEERLING; J.W. KLIJNSTRA \& Y. VAN VuGGT. 1990. Two related butterfly species avoid oviposition near each other's eggs. Experimentia 46: 526-528.

SHAPIRO, A.M. 1981. Egg-mimics of Streptanthus (Cruciferae) deter oviposition by Pieris sisymbrii (Lepidoptera: Pieridae). Oecologia 48: 142-143.

SINGER, M.C. 1986. The definition and measurement of oviposition preference in plant- feeding insects, p.65-94. In: J. MILLER \& T. MILLER (Eds). Insect-plant interactions. Spring-Verlag.

SOLOMON, B.P. 1981. Response of a host-specific herbivore to resource density, relative abundance, and phenology. Ecology 62: 1205-1214.

SWIHART, C.A. 1971. Colour discrimination by the butterfly Heliconius charitonius Linn. Anim. Behav. 19: 156-164.

THIÉRY, D. \& J.L.L. LEQUÉRE. 1991. Identification of an oviposition-deterring pheromone in the eggs of the European corn borer. Naturwissenschaften 78 : 132- 133.

ThiÉRY, D.; B. Gagel; P. Farkas \& V. Pronier. 1992. Identification of an oviposition-regulating pheromone in the European grapevine moth, Lobesia botrana (Lepidoptera: Tortricidae). Experientia 48: 697-699.

THOMAS, C.D. 1987. Behavioural determination of diet breadth in insect herbivores: the effect of leaf age on choice of host species by beetles feeding on Passiflora vines. Oikos 48: 211-216.

VASCONCELlos-NeTO, J. \& R.F. MONTEIRO. 1993. Inspection and evaluation of host plant by the butterfly Mechanitis lysimnia (Nymph., Ithomiinae) before laying eggs: a mechanism to reduce intraspecific competition. Oecologia 95: 431-438.

VINSON, S.B. 1981. Habitat location, p.51-77. In: N.A. NORDLUND; R.L. JONES \& W.J. LEWIS (Eds) Semiochemicals: their role in pest control. John Wiley \& Sons.

WELLINGS, P.W. 1991. Host location and oviposition on animals, p.75-107. In: W.J.

BAILEY \& J. RIDSDILL-SMITH (Eds). Reproductive behavior of insects: individuals and populations. Chapman \& Hall.

WIKLUND, C. 1975. The evolutionary relationship between adult oviposition preferences and larval host plant range in Papilio machaon L. Oecologia 18: 185-197.

WiKLUND, C. \& C. AHRBERG. 1978. Host plants, nectar source plants, and habitat selection of males and females of Anthocharis cardamines (Lepidoptera). Oikos 31: 169-183.

WiLliams, K.S. \& L.E. GilberT. 1981. Insects as selective agents on plant vegetative morphology: egg mimicry reduces egg laying by butterflies. Science 212: $467-469$. 